\title{
Observation of Gas-Phase Molecular Dications Formed from Neutral Organics in Solution via the Controlled-Current Electrolytic Process Inherent to Electrospray
}

\author{
Gary J. Van Berkel and Feimeng Zhou* \\ Chemical and Analytical Sciences Division, Oak Ridge National Laboratory, Oak Ridge, Tennessee, USA
}

\begin{abstract}
This article reports the first electrospray (ES) mass spectrometry observation of molecular dications that were formed in solution by sequential one-electron oxidation of the neutral molecules [viz., nickel(II) and cobalt(II) octaethylporphyrin] via the controlled-current electrolytic (CCE) process inherent to electrospray. Dication formation was found to require (1) the addition of electrolyte to the sample solution, which increased the magnitude of the ES current and, therefore, increased the extent of analyte electrolysis in the ES capillary, (2) a relatively low solution flow rate, which increased the electrolysis time (i.e., the time the analyte remained in the capillary), thereby providing more time for the analytes to diffuse to the metal-solution interface and react, and (3) the use of a platinum ES capillary, which, because it is difficult to oxidize, increased the proportion of the faradaic current that might be provided by electrolysis of solution species compared to that proportion available when the typical stainless steel capillary is used. These interpretations of the data are made on the basis of the known characteristics of the CCE process inherent to ES, supplementary data obtained from direct solution-phase observation of the metalloporphyrin redox products formed within the different metal ES capillaries by means of a novel ES ion source, and off-line cyclic voltammetry studies of the metalloporphyrins performed by using platinum and stainless steel working electrodes. (J Am Soc Mass Spectrom 1996, 7, 157-162)
\end{abstract}

$\mathrm{O}$ ur group has shown, as have a few other groups, that monocations and monoanions formed from neutral compounds in solution by chemical electron-transfer reactions [1-7] or by the controlled-current electrolytic (CCE) process inherent to electrospray [8-13] can be subsequently detected in the gas phase via electrospray mass spectrometry (ESMS). We also have reported that molecular dications $[4,6]$ as well as dianions [5] formed in solution via chemical electron-transfer methods can be detected by ES-MS. Both the chemical and electrochemical electron-transfer methods have been shown to be sensitive and, in particular cases, selective means to ionize in solution certain types of neutral analytes (e.g., highly conjugated, aromatic, and heteroaromatic compounds) for analysis by ES-MS. Moreover, these methods have provided means for the generation and analysis of different molecular ionic species than are normally the subject of ES-MS analyses (e.g., $\mathrm{M}^{+\cdot}$ and $\mathrm{M}^{2+}$ versus $\left[\mathrm{M}+\mathrm{H}^{+}\right]^{+}$and $\left.\left[\mathrm{M}+2 \mathrm{H}^{+}\right]^{2+}\right)$ and have provided

Address reprint requests to Dr. Gary J. Van Berkel, Chemical and Analytical Sciences Division, Oak Ridge National Laboratory, P.O. Box 2008/Bldg. 5510, Oak Ridge, TN 37831-6365.

* Current address: Department of Chemistry, University of Wisconsin -Eau Claire, Eau Claire, WI 54702. means for the generation of ions difficult to produce by using other ion sources (e.g., $\mathrm{M}^{2+}$ from $\beta$-carotene) [4]. In this paper, we report for the first time the ability to form dications (i.e., $\mathrm{M}^{2+}$ ) from neutral analytes in solution [viz. nickel(II) and cobalt(II) octaethylporphyrin ( $\mathrm{Ni}^{\mathrm{II}} \mathrm{OEP}$ and $\mathrm{Co}{ }^{\mathrm{II}} \mathrm{OEP}$, respectively)] via the CCE process inherent to electrospray (ES) and the ability to observe these ions in the gas-phase via ES-MS.

\section{Experimental}

All ES-MS experiments were carried out using a Finnigan-MAT (San Jose, CA) ion trap mass spectrometer (ITMS) adapted for ES-MS. Operation of the ES-ITMS and details of the analysis of metalloporphyrins via this instrumentation are discussed in detail elsewhere [14-16]: In brief, a syringe pump (Harvard Apparatus, Inc., Cambridge, MA) was used to pump analyte solutions through a short length of 254- $\mu \mathrm{m}$-i.d. Teflon ${ }^{\mathrm{TM}}$ tubing (Upchurch Scientific, Oak Harbor, WA) that connected via a low dead-volume PEEK ${ }^{\mathrm{TM}}$ union (254 $\mu \mathrm{m}$ through-hole; Upchurch) to either a dome-tipped 304 stainless steel capillary $(6.5 \mathrm{~cm}$ long, $127 \mu \mathrm{m}$ i.d., $500 \mu \mathrm{m}$ o.d., Scientific Instrument Services, Ringoes, $\mathrm{NJ})$ or a dome-tipped platinum capillary $(6.5 \mathrm{~cm}$ long, 
$210 \mu \mathrm{m}$ i.d., $400 \mu \mathrm{m}$ o.d.; Hamilton, Reno, NV) within a pneumatically assisted ES source. The capillary was held at a potential of $4.0 \mathrm{kV}$ and placed about $1.0 \mathrm{~cm}$ from the front aperture of the mass spectrometer. $\mathrm{Ni}$ trogen gas (Liquid Air Corp., Walnut Creek, CA), at a backing pressure of $20 \mathrm{lb} /$ in. $^{2}$, was used to pneumatically assist the ES process. The ES current was measured at the front aperture plate of the mass spectrometer by grounding this plate through a Keithley (Cleveland, $\mathrm{OH}$ ) model $610 \mathrm{C}$ electrometer. Voltages in the atmospheric sampling interface were optimized for transmission of the dication at the expense of monocation signal. In general, the interface conditions that maximized the dication signal were "gentle," in terms of the analyte ion-molecule collisions that occur in this region, relative to the conditions that maximized the monocation signal [15].

To acquire UV/visible spectra of the solution that exits the ES capillary, prior to the spraying process, we employed a novel ES setup that has been described in detail elsewhere [12]. In this particular work, a syringe pump was used to deliver the appropriate solution at 1.5 or $5.0 \mu \mathrm{L} / \mathrm{min}$ through $254-\mu \mathrm{m}$-i.d. Teflon ${ }^{\mathrm{TM}}$ tubing, to either the dome-tipped stainless steel or platinum capillary described in the preceding text, which were connected to the tubing via a low dead-volume PEEK $^{\mathrm{TM}}$ union. The downstream end of the metal capillary exited directly into the detector flow cell (4.5-mm pathlength, 5- $\mu \mathrm{L}$ volume) of a SoloNet140 $\mathrm{UV} /$ visible diode array detector (DAD) system (Groton Technology, Inc., Concord, MA) that was isolated from ground to allow the ES high voltage ( $5 \mathrm{kV}$ in this case) to be applied to the metal capillary. From the detector flow cell, the solution traveled through $30 \mathrm{~cm}$ of $100-\mu \mathrm{m}$-i.d. fused silica capillary before finally being sprayed, with pneumatic nebulization (nitrogen gas, 30-lb/in. ${ }^{2}$ backing pressure), toward a planar electrode ( $\sim 5$-mm separation of capillary and electrode) that was grounded through the Keithley electrometer. The diode array detector in this ES setup was operated by using only the visible lamp. With the UV lamp on at the low flow rates employed, photoionization-photobleaching of the porphyrins in the detector flow cell occurred because of the substantial time the analyte was in the path of the intense light source.

Stock solutions (500-1000 $\mu \mathrm{M})$ of the porphyrins (Aldrich, Milwaukee, WI) were prepared in high-performance liquid chromatography (HPLC)-grade methylene chloride (J. T. Baker, Phillipsburg, NJ). From these stock solutions, sample solutions were prepared for ES-MS or the ES-DAD experiments by dilution with methylene chloride, acetonitrile (J. T. Baker), and an acetonitrile solution of lithium trifluoromethane sulfonate (i.e., lithium triflate; Aldrich) to yield a final solution composition of about $5-10-\mu \mathrm{M}$ porphyrin in $1 / 1(\mathrm{v} / \mathrm{v})$ acetonitrile-methylene chloride that contained either $0-, 0.1-, 1.0-$, or $9.0-\mathrm{mM}$ lithium triflate. For cyclic voltammetry, sample solutions were prepared to yield a final solution composition of about $200-\mu \mathrm{M}$ porphyrin in $1 / 1(\mathrm{v} / \mathrm{v})$ acetonitrile-methylene chloride that contained about $50-\mathrm{mM}$ lithium triflate. Cyclic voltammograms were obtained by using a BAS 100 Electrochemical Analyzer (Bioanalytical Systems, Inc., West Lafayette, IN) and a scan rate of 200 $\mathrm{mV} / \mathrm{s}$. A platinum mesh was used as the auxiliary electrode and a silver wire was used as the quasireference electrode. Either a platinum disk electrode $(2 \mathrm{~mm}$ dia.) or a 316 stainless stecl capillary-borc union (model ZU1C, Valco, Houston, TX) was used as the working electrode. Ferrocene (Aldrich) was added to each sample solution for use as the reference redox system.

\section{Results and Discussion}

Shown in Figure 1a are the relative ion currents for the monocation $\left(I_{\mathrm{M}+}, \mathrm{m} / z 590\right)$ and dication $\left(I_{\mathrm{M} 2+}, \mathrm{m} / z\right.$ 295) of $\mathrm{Ni}$ "OEP recorded during six separate continuous infusion experiments that employed either platinum or stainless steel ES capillaries and different solution flow rates. (The first oxidation product of $\mathrm{Ni}^{\mathrm{II}} \mathrm{OEP}$ is an odd-electron species, i.e., $\mathrm{M}^{++}$. However, neutral $\mathrm{Co}^{\mathrm{II}} \mathrm{OEP}$ is paramagnetic; hence, the first oxidation product is an even-electron species, i.c., $\mathrm{M}^{+}$. To avoid confusion, the mono- and dications of both $\mathrm{Ni}^{\mathrm{II}} \mathrm{OEP}$ and $\mathrm{Co}^{\mathrm{Il}} \mathrm{OEP}$ will be referred to as $\mathrm{M}^{+}$and $\mathrm{M}^{2+}$, respectively.) Note that the dication is observed only when the platinum capillary is used, and the greatest intensity is observed at the lowest solution flow rate. Furthermore, the total porphyrin ion signal recorded, that is, $\left(I_{\mathrm{M}+}+I_{\mathrm{M} 2+}\right)$ (see Table 1 ), is greater at each flow rate when the platinum capillary is used, and $\left(I_{\mathrm{M}+}+I_{\mathrm{M} 2+}\right)$ recorded by using either capillary decreases as the flow rate increases from 1.5 to 5.0 $\mu \mathrm{L} / \mathrm{min}$. An additional point that cannot be ascertained from these data alone is the fact that the gasphase ion intensities recorded for the monocation greatly increase [13] and the dication first is observed only when electrolyte (i.e., lithium triflate) is added to the sample solution. For Ni"OEP, an electrolyte concentration of about $1.0 \mathrm{mM}$ was found to provide the best signal intensities for the porphyrin ions with minimal background noise. This increase in porphyrin ion signal upon the addition of electrolyte to the solution correlated with the resulting increase in the magnitude of the ES current $i_{\mathrm{ES}}$. The respective values of $i_{\mathrm{ES}}$ measured ( $\pm 15 \%$ relative standard deviation, RSD) at the front aperture plate of the mass spectrometer are shown in Figure 1 and Table 1. These currents are nearly identical for the two capillaries at the same flow rate. Figure $1 \mathrm{~b}$ is, the ES mass spectrum of $\mathrm{Ni}^{\mathrm{II}} \mathrm{OEP}$ obtained at a flow rate of $1.5 \mu \mathrm{L} / \mathrm{min}$ with the platinum capillary and serves to illustrate the signal-tobackground quality of the spectra. The only porphyrin ion other than the mono- or dication of significant abundance in this spectrum (or any of the other spectra recorded) is observed at $m / z 575$, which corresponds to a fragment of the monocation, that is, [M$15]^{+}$, formed via interface fragmentation [15]. 
Table 1. Summary of experimental and calculated data for the $\mathrm{Ni}$ "OEP experiments illustrated in Figure $1^{\mathrm{a}}$

\begin{tabular}{|c|c|c|c|c|c|c|c|c|c|}
\hline \multirow[b]{3}{*}{ Capillary } & \multirow{3}{*}{$\begin{array}{l}\text { Flow rate } \\
(\mu \mathrm{L} / \mathrm{min})\end{array}$} & \multicolumn{3}{|c|}{$i_{E S}(\mu A)$} & \multirow[b]{3}{*}{$I_{M+}{ }^{\prime}$} & \multirow[b]{3}{*}{$l_{\mathrm{M} 2+}{ }^{g}$} & \multirow[b]{3}{*}{$\left(I_{\mathrm{M}+}+I_{\mathrm{M} 2+}\right)^{\mathrm{h}}$} & \multirow{3}{*}{$\begin{array}{l}t_{0}{ }^{c} \\
(s)\end{array}$} & \multirow{3}{*}{$\begin{array}{l}t_{\mathrm{E}}^{\mathrm{C}} \\
\langle\mathrm{s}\rangle\end{array}$} \\
\hline & & \multirow[b]{2}{*}{ Measured $^{e}$} & \multicolumn{2}{|c|}{ Calc. for conversion to } & & & & & \\
\hline & & & $\mathrm{M}^{+}$ & $\mathrm{M}^{2+}$ & & & & & \\
\hline \multirow{3}{*}{$\begin{array}{c}\text { Stainless } \\
\text { steel }\end{array}$} & 1.5 & 0.15 & 0.019 & 0.039 & 100 & 0 & 70 & 8 & 33 \\
\hline & 2.5 & 0.21 & 0.032 & 0.064 & 73 & 0 & 52 & 8 & 20 \\
\hline & 5.0 & 0.30 & 0.064 & 0.13 & 51 & 0 & 36 & 8 & 10 \\
\hline \multirow{3}{*}{ Platinum } & 1.5 & 0.16 & 0.019 & 0.039 & 72 & 70 & 100 & 22 & 84 \\
\hline & 2.5 & 0.20 & 0.032 & 0.064 & 96 & 34 & 92 & 22 & 50 \\
\hline & 5.0 & 0.30 & 0.064 & 0.13 & 88 & 0 & 62 & 22 & 25 \\
\hline
\end{tabular}

a 8.0- $\mu \mathrm{M} \mathrm{Ni}$ "OEP dissolved in acetonitrile-methylene chloride $(1 / 1 \mathrm{v} / \mathrm{v})$ that contained $1.0-\mathrm{mM}$ lithium triflate.

bES current necessary for complete conversion of 8.0- $\mathrm{M}$ Ni"OEP to the monocation and dication calculated using eq 1 .

${ }^{c}$ Analyte diffusion time $t_{\mathrm{D}}=d_{D}^{2} / D$, where $d_{\mathrm{D}}$ is the diffusion distance corresponding to the internal radius $r_{\mathrm{C}}$ of the ES capillary and $D$ is a typical diffusion coefficient (i.e., $5 \times 10^{-6} \mathrm{~cm}^{2} / \mathrm{s}$ [19]).

Maximum electrolysis time $t_{E}=\pi r_{C}^{2} / 1 \%$, where $r_{C}$ is the internal radius of the capillary, $l$ is the length of the capillary, and $\nu$ is the solution flow rate through the ES capillary.

ES current measured at the front aperture plate of the mass spectrometer.

$1 / M_{-}$is the relative ES mass spectrum ion current recorded for the monocation.

$9 / /_{\mathrm{M} 2+}$ is the relative ES mass spectrum ion current recorded for the dication.

${ }^{h}\left(I_{M+}+I_{M 2+}\right)$ is the normalized total porphyrin ion current.

(a)

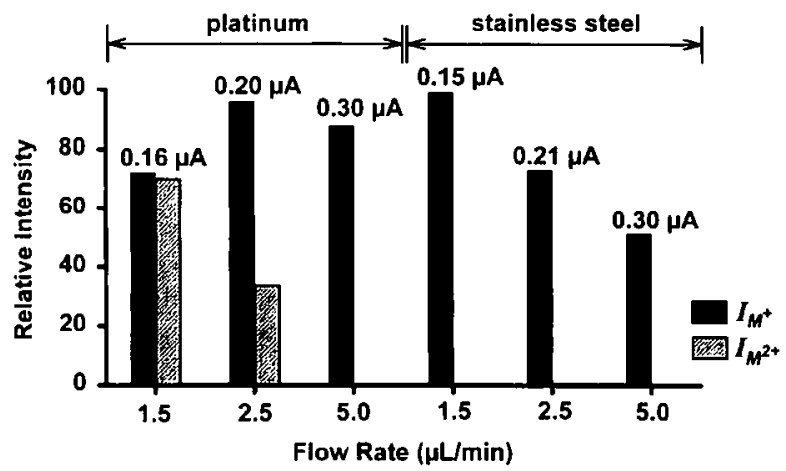

(b)

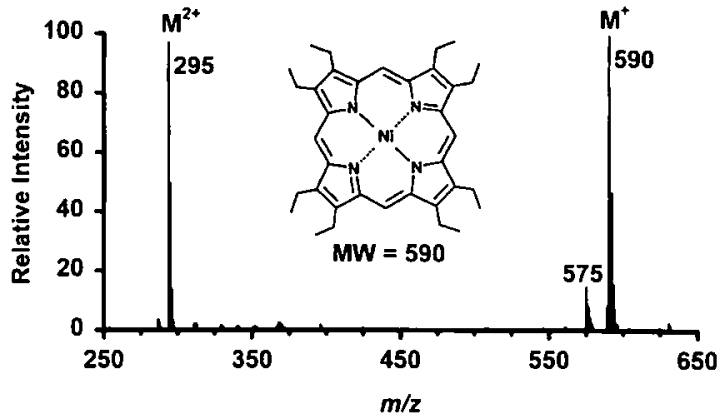

Figure 1. (a) Relative ion currents for the monocation $\left(l_{\mathrm{M}+}\right.$, $m / z 590)$ and dication $\left(I_{\mathrm{M} 2+}, m / z 295\right)$ of $\mathrm{Ni}^{11} \mathrm{OEP}(8.0 \mu \mathrm{M}$ in acetonitrile-methylene chloride that contained $1.0-\mathrm{mM}$ lithium triflate) recorded during six separate continuous infusion experiments that employed both a platinum and stainless steel ES capillary and solution flow rates of $1.5,2.5$, and $5.0 \mu \mathrm{L} / \mathrm{min}$. Intensities are normalized with respect to the largest monocation intensity recorded during the different experiments. Shown over the bars are the respective values of the ES current $i_{\mathrm{ES}}$, measured at the front aperture plate of the mass spectrometer. (b) ES mass spectrum of $\mathrm{Ni}$ "OEP obtained during the continuous infusion experiment carried out at $1.5 \mu \mathrm{L} / \mathrm{min}$ with the platinum capillary. ES high voltage $=4.0 \mathrm{kV}$.
The solution-phase electrolytic origin of these metalloporphyrin mono- and dications is supported by data that were obtained by direct observation of the $\mathrm{Ni}^{11}$ OEP solution used to acquire the data in Figure 1 as it exited the FS capillary of a specially designed ES-diode array detector setup (ES-DAD) [12]. Because operational conditions and ES behavior of the ES-DAD system are similar to those of the normal ES setup [12], the concentration of the ionic porphyrin species detected in solution with the ES-DAD should be similar to the concentration of these same species that exit the capillary in the normal ES setup, which we subsequently detected in the gas phase (Figure 1). The $\mathrm{UV} /$ visible spectra of $\mathrm{Ni}^{\mathrm{II}} \mathrm{OEP}$ shown in Figure 2 were obtained with the ES-DAD setup by using both the platinum (Figure 2a) and stainless steel (Figure 2b) ES capillaries. For reference, the spectrum of the neutral porphyrin (solid curve: $\lambda_{\max }=386 \quad\left(\varepsilon \approx 2.2 \times 10^{5}\right.$ $\left.\mathrm{L} / \mathrm{mol} \mathrm{cm}^{-1}\right), 510$, and $\left.548 \mathrm{~nm}[6,17,18]\right)$, obtained with the ES high voltage switched off, is shown in each case. With the platinum capillary (Figure 2a), the $\mathrm{UV} /$ visible spectrum obtained with the high voltage on at a flow rate of $5.0 \mu \mathrm{L} / \mathrm{min}$ (dashed curve) demonstrates complete conversion of the neutral to the radical cation as evidenced by the absence of the peaks at 386, 510, and $548 \mathrm{~nm}$ and the appearance of the absorbance peak diagnostic of the radical cation at 370 nm $\left(\varepsilon \approx 9.0 \times 10^{4} \mathrm{~L} / \mathrm{mol} \mathrm{cm}^{-1}[6,17,18]\right)$. Because ES behaves as a CCE cell [12] and because the potentials required for formation of the mono- and dication of $\mathrm{Ni}^{\mathrm{Hi}} \mathrm{OEP}$ are sufficiently separated (about $0.5 \mathrm{~V}$ for $\mathrm{Ni}$ "OEP; see subsequent text), the potential at the metal-solution interface within the ES capillary will shift to a value sufficiently positive to form the dication only after all the neutral porphyrin is oxidized to the monocation. This is apparently the case when the flow rate is reduced to $1.5 \mu \mathrm{L} / \mathrm{min}$ : the spectrum then recorded (dotted curve) shows a decrease in the inten- 
sity of the absorption peak at $370 \mathrm{~nm}$, which we believe is indicative of oxidation of the monocation to the dication. This interpretation is consistent with the data in Figure 1, which show that the dication is observed in the gas phase at a flow rate of $1.5 \mu \mathrm{L} / \mathrm{min}$, but not at $5.0 \mu \mathrm{L} / \mathrm{min}$. Unfortunately, a UV/visible

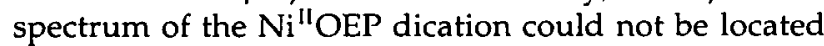
in the literature to confirm this hypothesis.

The UV/visible spectra in Figure $2 b$ demonstrate that for a given set of conditions, the extent of porphyrin electrolysis within the stainless steel capillary is less than that observed within the platinum capillary. Note that this is true even though the magnitude of $i_{\mathrm{ES}}$ (which ultimately limits the extent of electrolysis [12]) recorded with stainless steel capillary is slightly higher in this particular case than $i_{\text {ES }}$ recorded when using the platinum capillary. At a flow rate of $5.0 \mu \mathrm{L} / \mathrm{min}$, the spectrum recorded with the high voltage on (dashed line) indicates the presence of both the neutral compound (peaks at 386, 510, and $548 \mathrm{~nm}$ ) and the monocation (low wavelength tail on the peak centered at $386 \mathrm{~nm}$ ). Reduction of the flow rate to $1.5 \mu \mathrm{L} / \mathrm{min}$ results in more extensive electrolysis of the porphyrin, but the appearance of the spectrum indicates that a substantial fraction of the analyte that exits the stainless steel capillary is still the neutral molecule. This observation coincides with the observed increase in

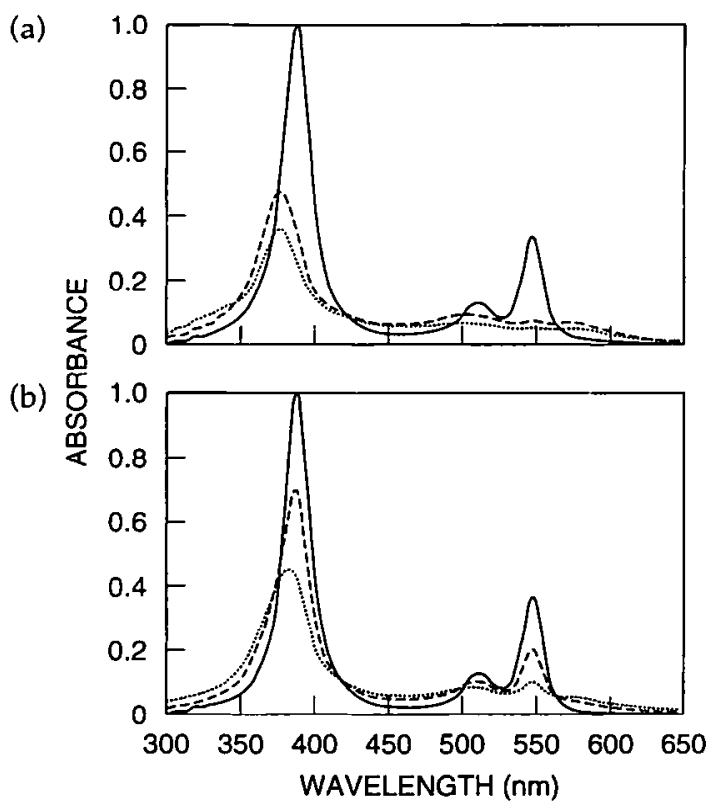

Figure 2. UV/visible spectra of $\mathrm{Ni}^{\prime \prime} \mathrm{OEP}(8.5 \mu \mathrm{M}$ in acetonitrile-methylene chloride that contained $1.0-\mathrm{mM}$ lithium triflate) obtained during continuous infusion experiments with the ESDAD setup with a high voltage of $5.0 \mathrm{kV}$, solution flow rates of $5.0 \mu \mathrm{L} / \mathrm{min}$ (dashed curves) and $1.5 \mu \mathrm{L} / \mathrm{min}$ (dotted curves), and either (a) the platinum capillary $\left(i_{\mathrm{ES}}=0.45 \mu \mathrm{A}\right.$ at both flow rates) or (b) the stainless steel capillary ( $i_{E S} \approx 0.52 \mu \mathrm{A}$ at both flow rates). For reference, the solid line spectra in (a) and (b) are that of the neutral Ni ${ }^{11}$ OEP ( $\lambda_{\max }=386,510$, and $548 \mathrm{~nm}$ ) obtained with the ES high voltage switched off at a flow rate of 5.0 $\mu \mathrm{L} / \mathrm{min}$. total porphyrin gas-phase ion signal with decreasing flow rate (Figure 1, Table 1). Moreover, because neutral porphyrin remains in solution, the dication will not be formed, which is consistent with the observed absence of dication in the gas phase under similar ES-MS operational conditions.

We previously demonstrated that the molecular monocation of $\mathrm{Ni}^{11} \mathrm{OEP}$ could be formed in solution by one-electron electrolytic oxidation of the neutral porphyrin via the CCE process inherent to ES and that these ions subsequently could be observed in the ES mass spectrum $[9,12,13]$. However, previously we were not able to form the dication and observe it in the gas phase because we did not use the proper combination of ES-MS operational parameters, namely, $i_{\mathrm{ES}}$, solution flow rate, and ES capillary material. The conditions necessary for formation and observation of the $\mathrm{Ni}{ }^{11} \mathrm{OEP}$ dication can be understood in terms of the diffusion-limited transport of the analyte for reaction at the metal-solution interface within the ES capillary and in terms of the current-limited nature of the electrolytic process inherent to ES [12]. Comparison of an estimated maximum analyte diffusion time $t_{D}$ and the time the analyte remains in the capillary, that is, the maximum electrolysis time $t_{E}$, at the various flow rates (Table 1) indicates that the porphyrin molecules throughout the capillary should have sufficient time to diffuse to the metal-solution interface for reaction, even at a flow rate of $5.0 \mu \mathrm{L} / \mathrm{min}$ (i.e., $t_{\mathrm{D}}<t_{\mathrm{E}}$ ). This finding is corroborated by the ES-DAD data in Figure $2 a$ that shows full conversion of $\mathrm{Ni}$ IIOEP to the monocation at $5.0 \mu \mathrm{L} / \mathrm{min}$ when the platinum capillary is used. However, efficient formation of the dication requires a longer electrolysis time than formation of the monocation because, as mentioned previously, all the neutral porphyrin must be converted to the monocation before the dication will be formed. Therefore, the initially formed monocations that diffuse away from the interface after their formation or are expelled by the positively charged ES capillary (migration effect) must make their way back to the interface for further reaction once all the available neutral porphyrin is converted to the monocation. If we assume the migration effect can be ignored (a valid assumption given that the electrolyte concentration is higher than the concentration of the analyte), the electrolysis time necessary for efficient formation of the dication could be at least twice the diffusion time shown in Table 1. In fact, the dications are observed only at the flow rates where $t_{\mathrm{E}}>2 t_{\mathrm{D}}$.

The current-limited nature of the electrolytic process is expressed by Faraday's law shown in eq 1:

$$
i_{\mathrm{ES}}=i_{\mathrm{F}}=\sum_{j} n_{j} A_{j} F \nu
$$

where $n_{j}$ is the number of electrons involved in the oxidation of one molecule of species $j, A_{j}$ is the concentration of species $j$ oxidized, $F$ is the Faraday 
constant $\left(9.648 \times 10^{4} \mathrm{C} / \mathrm{mol}\right)$, and $\nu$ is the solution flow rate through the ES capillary. From this equation it can be seen that $i_{\mathrm{ES}}$, and the current due to the electrolysis reactions in the capillary, that is, the faradaic current $i_{F}$, are equal in magnitude and directly proportional to the total amount of material that reacts to supply the current. With reference to the $\mathrm{Ni}{ }^{\mathrm{II}}$ OEP data in Figure 1 and calculations based on eq 1 (Table 1), the magnitude of $i_{\mathrm{ES}}$ measured at all three flow rates should be sufficient for complete oxidization of the $\mathrm{Ni}^{\text {II }} \mathrm{OEP}$ to the dication, provided that it is available for reaction and no reactions other than porphyrin oxidation supply $i_{F}$. (Note that complete electrolysis was not possible with little or no electrolyte added to the solution because of the much lower magnitudes of $i_{\mathrm{ES}}$.) In the case of the platinum capillary, we see in the mass spectra the dication at the low flow rates where the porphyrin is available for reaction, although the conversion efficiency is not $100 \%$ (i.e., both $\mathrm{M}^{+}$and $\mathrm{M}^{2+}$ are observed). However, in the case of the stainless steel capillary, the dication is not observed and the total porphyrin ion signal is less at each flow rate than that recorded with the platinum capillary. This indicates that some other reactions must be supplying faradaic current that might otherwise be supplied by porphyrin oxidation. We believe that at least one of these reactions is the oxidation of iron in the stainless steel capillary.

This hypothesis is supported by the work of Kebarle and co-workers [8], who have shown that a substantial fraction, if not all, of the faradaic current in an ES source may be supplied by oxidation of the iron in the stainless steel capillary. We found that the cyclic voltammograms (CVs; not shown) of $\mathrm{Ni}^{\mathrm{II}} \mathrm{OEP}$ obtained by using stainless steel and platinum working electrodes also supported this contention. The CV data showed that both the monocation and dication of $\mathrm{Ni}{ }^{\text {II }}$ OEP could be formed at a platinum working electrode in acetonitrile-methylene chloride $(1 / 1 \mathrm{v} / \mathrm{v})$ as evidenced by two distinct and characteristic anodic waves $\left(\mathrm{Ni}{ }^{11} \mathrm{OEP}\right.$ peak potentials: $E_{\mathrm{pa} 1}=0.84 \mathrm{~V}$ and $E_{\mathrm{pa} 2}=1.37 \mathrm{~V}$ versus SCE [6]). Consistent with the expected behavior in this solvent system [19], there was no evidence for oxidation of the platinum within this potential range. In contrast, neither the oxidation wave for the porphyrin nor the wave due to oxidation of the redox reference ferrocene ( $E=0.31 \mathrm{~V}$ versus SCE [19]) could be discerned in the $\mathrm{CV}$ of $\mathrm{Ni}^{\mathrm{II}} \mathrm{OEP}$ recorded with a stainless steel working electrode. This was because of an anodic current that at approximately $0.8 \mathrm{~V}$ began to increase dramatically and continued to increase with increasing potential. Such behavior is indicative of the occurrence of a non-diffusion-controlled oxidation process that we believe is the oxidation of iron (and possibly other metals, e.g., chromium, nickel, or manganese) in the stainless steel electrode. This current begins to increase rapidly at about the same potential needed to form the monoca-

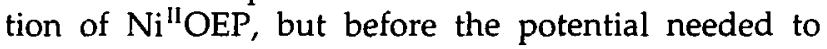

form the dication. Thus, in an ES ion source, one may surmise that oxidation of solution species whose redox potentials are greater than about $0.8 \mathrm{~V}$, such as the dication $\mathrm{Ni}^{\mathrm{Il}} \mathrm{OEP}$, will be precluded when a stainless steel ES capillary is used because the major portion of $i_{\mathrm{F}}$ may be supplied by reaction of the more easily oxidized capillary material. By using the ES capillary fabricated from platinum, which is much more difficult to oxidize than the components of stainless steel, a greater fraction of $i_{\mathrm{F}}$ may be supplied by oxidation of solution species. Oxidation of the components of the stainless steel capillary at about $0.8 \mathrm{~V}$ also is consistent with earlier observations that noted the efficiency of the CCE process for analyte ionization-detection in ES-MS rapidly decreased for species with redox potentials greater than about $0.6 \mathrm{~V}[9,11]$.

As might be predicted on the basis of the foregoing discussion, a similar ES-MS data set, which is summarized in Figure 3, was obtained by using $\mathrm{Co}^{\text {II }} \mathrm{OEP}$ as the analyte. In this case, however, the "cleanest" spectra that contained the dication were obtained with $0.1-\mathrm{mM}$ lithium triflate in the solution (Figure 3b). Higher concentrations of the electrolyte, which increased the magnitude of $i_{\mathrm{ES}}$ and the signal levels for both the mono- and dication at all flow rates, resulted in the production of significant background noise. At this point we have not delineated the origin of these background ions. However, because the dication of

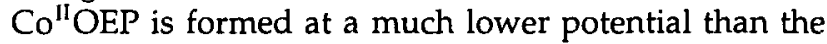
dication of $\mathrm{Ni}{ }^{\mathrm{II}} \mathrm{OEP}$ (Co ${ }^{\text {II }} \mathrm{OEP}$ peak potentials: $E_{\text {pal }}=$ 0.76 versus $\mathrm{SCE}$ and $E_{\mathrm{pa} 2}=0.92 \mathrm{~V}$ versus SCE [6]), these ions possibly might result from the further oxidation of the dication. It should be noted also in this case that the magnitude of $i_{\mathrm{ES}}$ recorded with the platinum capillary is higher at each flow rate than the current recorded with the stainless steel capillary. This difference might be explained by slightly different positions of the ES capillaries relative to the front aperture plate of the mass spectrometer or possibly by differences in the electrolysis reactions that take place in the two capillaries that lead to different solution compositions and, therefore, different magnitudes of $i_{\text {ES }}$ [13]. Nonetheless, the observed variations in the magnitude of $i_{\mathrm{ES}}$ recorded with the platinum and stainless steel capillaries under the various ES-MS operational conditions used in this work probably merit further study.

\section{Conclusions}

We have shown that the dications of $\mathrm{Ni}^{11} \mathrm{OEP}$ and $\mathrm{Co}^{\mathrm{II}} \mathrm{OEP}$ can be formed in solution via the CCE process inherent to ES and that they can be observed in the gas phase when ES-MS operational parameters are such that the faradaic current $\left(i_{\mathrm{ES}}=i_{\mathrm{F}}\right)$ is sufficient for complete electrolysis of the porphyrin to the dication, the porphyrin is available for reaction at the metal-solution interface within the capillary, and the reaction of no other species in the system can supply 
(a)

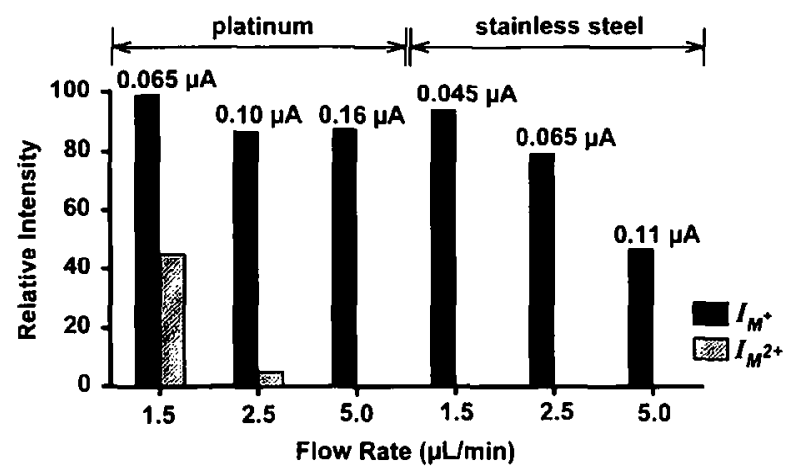

(b)

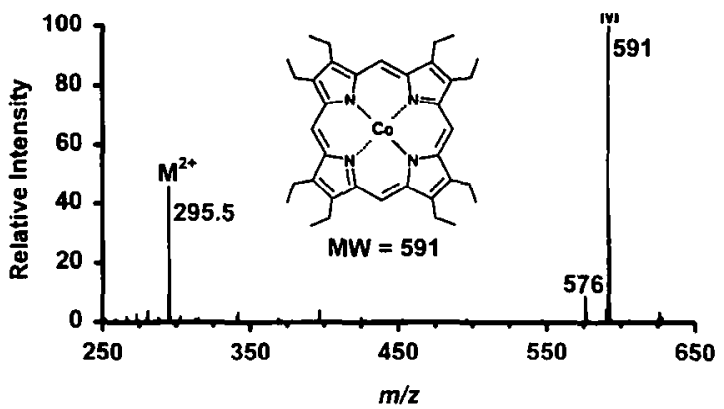

Figure 3. Relative ion currents for the monocation $\left(l_{\mathrm{M}+}, m /=\right.$ 591) and dication $\left(I_{\mathrm{M} 2+}, m / z 295.5\right)$ of Co"OEP $(7.0 \mu \mathrm{M}$ in acetonitrile-methylene chloride that contained $0.1-\mathrm{mM}$ lithium triflate) recorded during six separate continuous infusion experiments that employed both a platinum and stainless steel ES capillary and solution flow rates of $1.5,2.5$, and $5.0 \mu \mathrm{L} / \mathrm{min}$. Intensities are normalized with respect to the largest monocation intensity recorded during the different experiments. Shown over the bars are the respective values of the ES current $i_{E S}$, measured at the front aperture plate of the mass spectrometer. (b) ES mass spectrum of $\mathrm{Co}^{\mathrm{II}} \mathrm{OEP}$ obtained during the continuous infusion experiment carried out at $1.5 \mu \mathrm{L} / \mathrm{min}$ with the platinum capillary. ES high voltage $=4.0 \mathrm{kV}$.

faradaic current that might otherwise be used to oxidize the porphyrin. These operational conditions were achieved by the addition of electrolyte to the sample solution, which increased the magnitude of the $i_{\mathrm{ES}}$, the use of relatively low solution flow rates, which provided more time for the porphyrins to diffuse to the metal-solution interface and react, and the use of a platinum ES capillary, which increased the proportion of $i_{\mathrm{F}}$ supplied by electrolysis of the porphyrins when compared to that proportion supplied when a more easily oxidized stainless steel capillary is used. In general, these operational parameters should enhance the formation-detection of ions originally neutral in solution by ES-MS. This enhancement will be the result of both the increased analyte electrolysis efficiency under a given set of ES conditions and the ability to efficiently create-detect ionic species with ES-MS, such as the dication of $\mathrm{Ni}^{\mathrm{II}} \mathrm{OEP}$, that have relatively high redox potentials (i.e., $E>1.0 \mathrm{~V}$ versus $\mathrm{SCE}$ ).

\section{Acknowledgments}

The authors thank Dr. Scott A. McLuckey and Dr. Michelle V. Buchanan (ORNL) for critical review of the manuscript. F.Z. acknowledges an appointment to the United States Department of Energy (USDOE), Laboratory Cooperative Postgraduate Research Training Program, administered jointly by the Oak Ridge Institute for Science and Education (ORISE) and ORNL. This research was sponsored by the U.S. Department of Energy, Office of Basic Energy Sciences under contract DE-AC05-84OR21400 with Lockheed Martin Energy Systems, Inc.

\section{References}

1. Van Berkel, G. J.; McLuckey, S. A.; Glish, G. L. Anal. Chem. 1991, 63, 2064-2068.

2. Anacleto, J. F.; Quilliam, M. A.; Boyd, R. K.; Howard, J. B.; LaFleur, A. L.; Yadav, T. Rapid Commun. Mnss Spectrom. 1993, 7, 229-234.

3. Van Berkel, G. J.; Asano, K. G. Anal. Chem. 1994, 66, 2096-2102.

4. Van Berkel, G. J.; Asano, K. G.; McLuckey, S. A. J. Am. Soc. Mass Spectrom. 1994, 5, 689-692.

5. Zhou, F.; Van Berkel, G. J.; Donovan, B. T. J. Am. Chem. Soc. 1994, 116, 5485-5486.

6. Van Berkel, G. J.; Zhou, F. Anal. Chem. 1994, 66, 3408-3415.

7. Bond, A. M.; Colton, R.; Fiedler, D. A.; Kevekordes, J. E.; Tedesco, V.; Mann, T. F.; Inorg. Chem. 1994, 33, 5761-5766.

8. Ikonomou, M. G.; Blades, A. T.; Kebarle, P. Anal. Chem. 1991, 63, 1989-1998.

9. Van Berkel, G. J.; McLuckey, S. A.; Glish, G. L. Anal. Chem. 1992, 64, 1586-1593.

10. Dupont, A.; Gisselbrecht, J-P.; Leize, E.; Wagner, L.; Van Dorsselar, A. Tetrahedron Lett. 1994, 35, 6083-6086.

11. Xu, X.; Nolan, S. P.; Cole, R. B. Anal. Chem. 1994, 66, 119-125.

12. Van Berkel, G. J.; Zhou, F. Anal. Chem. 1995, 67, 2916-2923.

13. Van Berkel, G. J.; Zhou, F. Anal. Chem. 1995, 67, 3958-3964.

14. Van Berkel, G. J.; Glish, G. L.; McLuckey, S. A. Anal. Chem. 1990, 62, 1284-1295.

15. Van Berkel, G. J.; McLuckey, S. A.; Glish, G. L. Anal. Chem. 1991, 63, 1098-1109.

16. Van Berkel, G. J.; Quinoñes, M. A.; Quirke, J. M. E. Energy Fuels 1993, 7, 411-419.

17. Smith K. M., Ed. Porphyrins and Metalloporphyrins; Elsevier; Amsterdam, 1975.

18. Fuhrhop, J.-H.; Mauzerall, D. I. Am. Chem. Soc, 1969, 91, 4174-4181.

19. Bard, A. J.; Faulkner, L. R. Electrochemical Methods; Wiley: New York, 1980 